\title{
Design of Dual Band Rectangular Microstrip Antenna with C-Shaped Defected Ground Structure
}

\author{
Gurpreet Singh \\ Lecturer ECE Deptt. \\ Govt. Polytechnic College, \\ (Ferozepur)
}

\author{
Ranjit Singh Momi \\ Sen. Lect. \& Head ECE Deptt. \\ YRS Polytechnic College, \\ (Moga)
}

\author{
Deepak Kumar Syal \\ Lecturer ECE Deptt. \\ YRS Polytechnic College, \\ (Moga)
}

\begin{abstract}
In this research paper, the design of C-shaped Defected Ground Structure (DGS) antenna is proposed to realize dualband characteristics for C-band and X-band applications. The proposed antenna consists of $\mathrm{C}$-shaped slot incorporated in ground plane which resonates at two different frequencies $\left(\mathrm{f}_{\mathrm{r} 1}\right.$ and $\mathrm{f}_{\mathrm{r} 2}$ ) of $7.41 \mathrm{GHz}$ and $9.28 \mathrm{GHz}$ which lie in C-band and $\mathrm{X}$-band respectively. A very good return loss $\left(\mathrm{S}_{11}\right)$ of -30.79 $\mathrm{dB}$ and $-40.75 \mathrm{~dB}$ are obtained at first and second resonant frequencies respectively for C-shaped DGS antenna. The Bandwidth of C-shaped DGS antenna is increased by 825 $\mathrm{MHz}$ and $1182.8 \mathrm{MHz}$ respectively at two different bands than the bandwidth of the Conventional Rectangular Microstrip Patch Antenna (CRMPA). Also VSWR is much improved with C-shaped DGS antenna. The comparison of simulated results of proposed and CRMPA has also been presented in this paper. The main contribution of this paper is the miniaturization of ground plane of $23 \%$ using C-shaped DGS which is very much encouraging.
\end{abstract}

\section{General Terms}

Bandwidth (B.W.), Return loss $\left(\mathrm{S}_{11}\right)$, Voltage Standing Wave Ratio (VSWR), Peak Gain, Characteristic Impedance and Radiation Pattern.

\section{Keywords}

Defected Ground Structure (DGS) and Conventional Rectangular Microstrip Patch Antenna (CRMPA).

\section{INTRODUCTION}

In the literature, the Conventional Microstrip Patch Antenna (CRMPA) has attractive features of low profile, easy fabrication, light weight and conformability to mounting hosts. Microstrip antennas inherently have narrow bandwidth, but an enhancement of bandwidth is usually required in practical applications [1]. Studies to get compact and broadband operations of microstrip antennas have increased greatly. To enhance the impedance bandwidth, the monopole with different shapes is used [1-4]. According to the open literatures, the shape of conventional square monopole was changed to triangular and disc-shaped so as to improve impedance bandwidth. When the microstrip-fed monopole antenna is considered, besides the change of patch shape, the impedance matching network can be easily incorporated with the microstrip feedline to realize wider impedance bandwidth. Several methods have been considered in the literature for dual band operation of the antennas [5-13].

Recently, there has been an increasing interest in the use of Defected Ground Structure (DGS) for performance enhancement of microstrip antennas and arrays. They are realized by etching off a simple shape defect from the ground plane of the microstrip antenna. Depending on the shape and dimensions of the defect, the shielded current distribution in the ground plane is disturbed, resulting in a controlled excitation and propagation of the electromagnetic waves through the substrate layer. The shape may vary from a simple geometry to a complicated one. Due to its resonant behavior, the DGS may be compared to the LC parallel resonator, i.e., the equivalent circuit of the DGS consists of an inductance and a capacitance in parallel to itself [14]. A new approach using the defect in the ground plane of microstrip antenna has been presented in this work.

In this paper, C-Shaped slot is etched off from ground plane, which disturbs shielded current distribution in ground plane [15] and helps an antenna to resonate at two different resonating frequencies which lies in different frequency bands i.e. C-band and X-band with an enhancement of bandwidths. Proposed antenna finds its applications in satellite communications, RADAR and by some Wi-Fi devices.

This paper is organized in four sections. First section gives the introduction about Defected Ground Structure (DGS). In second section, structure of the proposed C-shaped DGS antenna and CRMPA are discussed which include their dimensions and material used. In third section, simulation results of both antennas have been presented in terms of Return Loss $\left(\mathrm{S}_{11}\right)$, Bandwidth, Peak Gain, Impedance $\left(\mathrm{Z}_{11}\right)$ and Radiation Pattern. Last section is the conclusion in which the advantages and application of the proposed antenna is discussed.

\section{ANTENNA DESIGN}

Both CRMPA and C-shaped DGS antennas are designed on 'Rogers RT/Duroid 5880 tm' substrate with thickness $\left(\mathrm{h}_{\mathrm{s}}\right)$ of $0.794 \mathrm{~mm}$ having relative permittivity $\left(\varepsilon_{\mathrm{r}}\right)$ of 2.2 . The design of a single band CRMPA using mirostrip feed satisfies the optimal geometrical parameters mentioned in Table 1 . The patch has the dimensions of $12.45 \times 16 \mathrm{~mm}^{2}$ with height $\left(\mathrm{h}_{\mathrm{p}}\right)$ of $0.05 \mathrm{~mm}$. The ground has the dimensions of $28.1 \times 32 \mathrm{~mm}^{2}$ with height $\left(\mathrm{h}_{\mathrm{g}}\right)$ of $0.05 \mathrm{~mm}$. An antenna is excited with microstrip feed having characteristics impedance of $50 \Omega$. The feed has dimension of $8 \times 2.46 \mathrm{~mm}^{2}$ with height $\left(\mathrm{h}_{\mathrm{f}}\right)$ of 0.05 $\mathrm{mm}$. The complete geometry of CRMPA is shown in Fig. 1 .

All the geometrical parameters of proposed C-shaped DGS antenna are same as that of CRMPA as mentioned in Table 1 except the C-shaped slot which is etched off form ground plane as shown in Fig. 2. This C-shaped slot consists of horizontal and vertical arms. The upper and lower horizontal arms have same dimensions of $5 \times 15 \times 0.05 \mathrm{~mm}^{3}$, whereas the vertical arm has dimensions of $24.1 \times 5 \times 0.05 \mathrm{~mm}^{3}$. Also C- 
shaped DGS in the ground plane found to give a size reduction of about $23 \%$ along with reduction in weight. The complete geometry of proposed C-slot DGS antenna is shown in Fig. 2. The Table 1 shows some common optimal geometrical parameters for both CRMPA and C-shaped DGS antennas.

Table 1. Optimal geometrical parameters for CRMPA and $C$-shaped DGS antennas

\begin{tabular}{|l|c|}
\hline \multicolumn{1}{|c|}{ Parameters } & Values \\
\hline Solution Frequency & $7.5 \mathrm{GHz}$ \\
\hline Dimensions of Ground $\left(\mathrm{mm}^{3}\right)$ & $28.1 \times 32 \times 0.05$ \\
\hline Dimensions of Substrate $\left(\mathrm{mm}^{3}\right)$ & $28.1 \times 32 \times 0.794$ \\
\hline Dimensions of Patch $\left(\mathrm{mm}^{3}\right)$ & $12.45 \times 16 \times 0.05$ \\
\hline Dimensions of Feed $\left(\mathrm{mm}^{3}\right)$ & $2.46 \times 8 \times 0.05$ \\
\hline Dimension of Boundary $\left(\mathrm{mm}^{3}\right)$ & $48.1 \times 52 \times 20.794$ \\
\hline
\end{tabular}

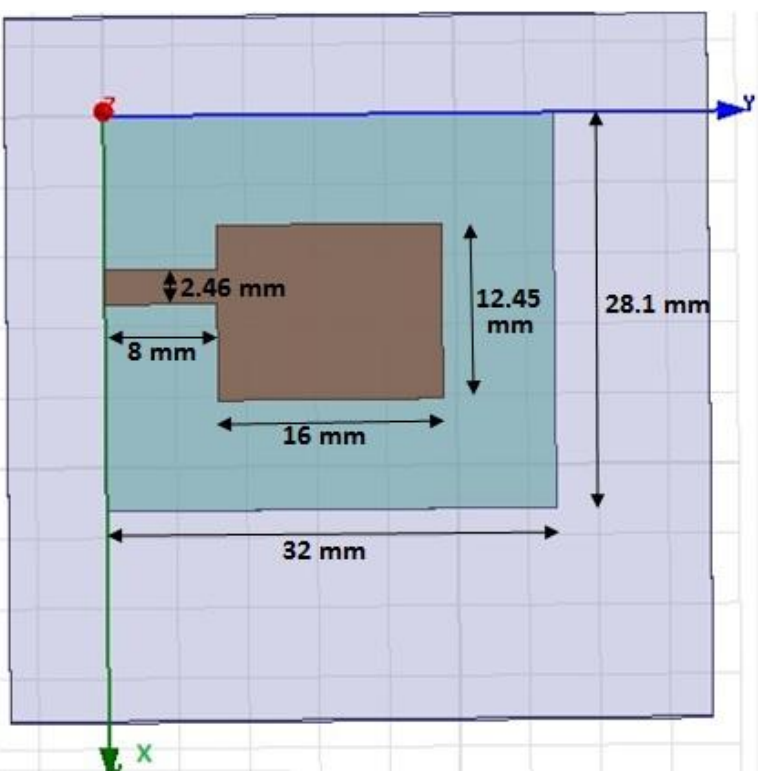

Fig 1: Geometry of CRMPA antenna

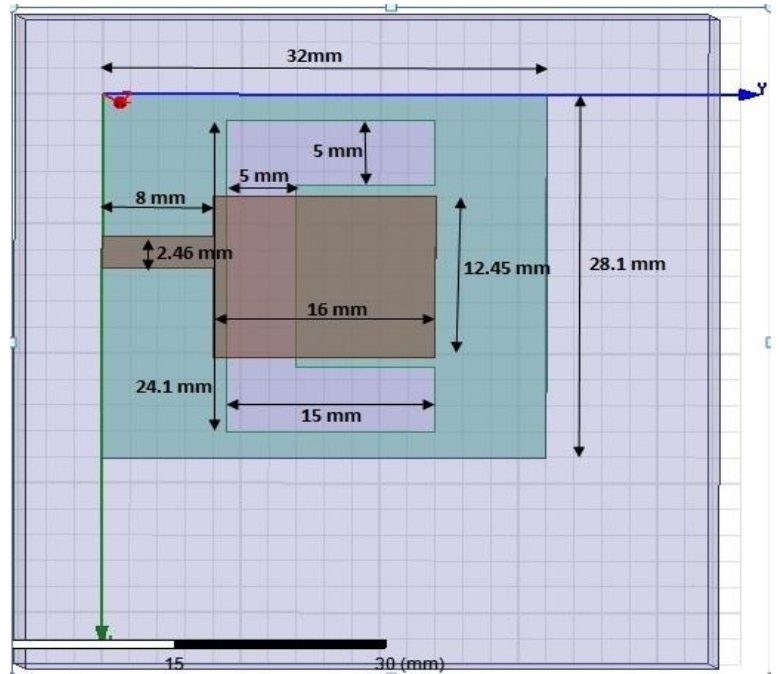

Fig 2: Geometry of C-shaped DGS antenna

\section{RESULTS AND DISCUSSIONS}

The electromagnetic solver, Ansoft High Frequency Structure Simulator (HFSS) software Version-13.0 based on Finite Element Method (FEM) is used to numerically investigate and optimize the reference and proposed antenna configuration.

\subsection{Return loss $\left(\mathbf{S}_{11}\right)$ and Bandwidth}

In Fig. 3, the continuous line shows that when $\mathrm{C}$-shaped slot is etched off from ground plane, the proposed antenna not only resonates in C-band but also excite one more band which resonates in $\mathrm{X}$-band. For $\mathrm{C}$-shaped DGS antenna, the simulated resonating frequency of first band $\left(f_{r 1}\right)$ is 7.4174 $\mathrm{GHz}$ which lies in $\mathrm{C}$-band, while the resonating frequency of second band $\left(\mathrm{f}_{\mathrm{r} 2}\right)$ is $9.2893 \mathrm{GHz}$ which lies in X-band. A very good return loss of $-30.79 \mathrm{~dB}$ and $-40.75 \mathrm{~dB}$ are obtained for first and second resonating frequency respectively. In case of C-shaped DGS antenna, the simulated impedance bandwidths across first and second bands are $914 \mathrm{MHz}(7.9903-7.0764$ $\mathrm{GHz})$ and $1.1828 \mathrm{GHz}(9.9289-8.7461 \mathrm{GHz})$ respectively

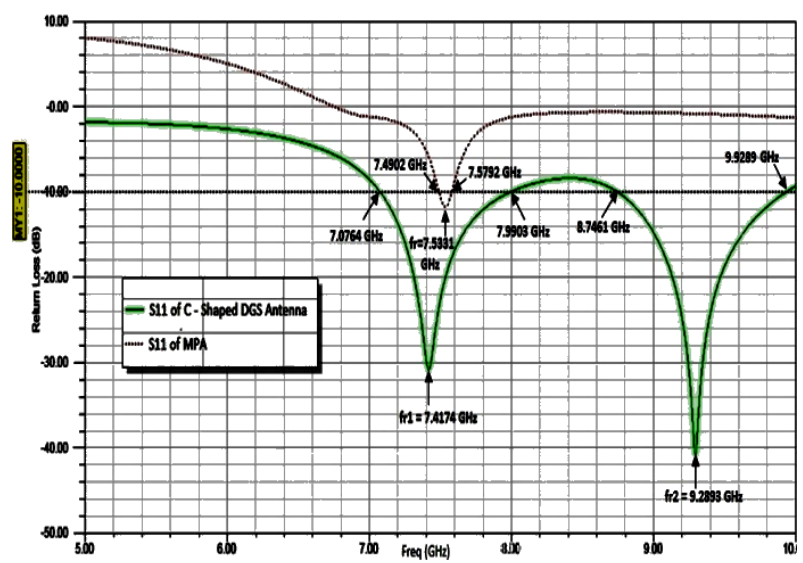

Fig 3: Simulated $S_{11}$ v/s frequency plot for CRMPA and CShaped DGS antennas

Vividly, in case of CRMPA i.e. antenna structure without slotting in ground, the antenna only resonates in the C-band at fundamental resonant frequency $\left(f_{r}\right)$ of $7.53 \mathrm{GHz}$ shown by dotted line in Fig. 3. The bandwidth of the CRMPA at operating band with same dimensions as mentioned in Table 1 is $89 \mathrm{MHz}(7.5792-7.4902 \mathrm{GHz})$ and also results in poor return losses $\left(\mathrm{S}_{11}\right)$ of $-11.78 \mathrm{~dB}$.

Thus it has been concluded that the Bandwidth of C-Shaped DGS antenna is increased by $825 \mathrm{MHz}$ and $1.0938 \mathrm{GHz}$ respectively at two different bands than the bandwidth of the CRMPA. Also return losses are improved at large extent for both of bands.

\subsection{VSWR}

In Fig. 4, the continuous line shows VSWR plot of the proposed C-shaped DGS antenna. For C-shaped DGS antenna, the simulated value of VSWR is 1.05 at first resonating frequency $\left(\mathrm{f}_{\mathrm{r} 1}\right)$ of $7.4174 \mathrm{GHz}$, while at second resonating frequency $\left(\mathrm{f}_{\mathrm{r} 2}\right)$ of $9.2893 \mathrm{GHz}$, the VSWR is 1.01 . At both resonating frequencies, the value of VSWR is approximately equal to 1 due to which proposed antenna results in perfect impedance matching. 


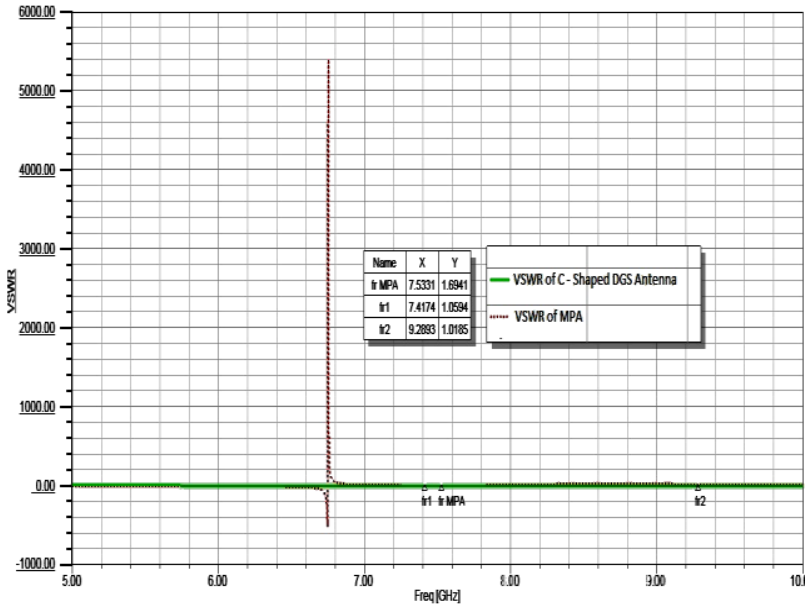

Fig 4: Simulated VSWR v/s frequency plot for CRMPA and C-Shaped DGS antennas

While in case of CRMPA, the simulated value of VSWR is 1.69 at resonating frequency $\left(\mathrm{f}_{\mathrm{r}}\right)$ of $7.53 \mathrm{GHz}$ as shown by dotted line in Fig. 4. As the value of VSWR is more than 1.5 which results in poor impedance matching.

\subsection{Impedance $\left(\mathrm{Z}_{11}\right)$}

For an efficient transfer of energy, the impedance of the antenna and of feed line connecting them must be the same. Transceivers and their transmission lines are typically designed for impedance of $50 \Omega$. In Fig. 5, continuous line shows that the simulated impedance $\left(\mathrm{Z}_{11}\right)$ of $\mathrm{C}$-shaped DGS antenna at the center frequencies $7.41 \mathrm{GHz}$ and $9.92 \mathrm{GHz}$ are $52.75 \Omega$ and $50.52 \Omega$ respectively; these are very close to the expected $50 \Omega$. While in case of CRMPA, the simulated impedance is $82.04 \Omega$ at resonating frequency $7.53 \mathrm{GHz}$ as shown by dotted line in Fig. 5 which further affects the return loss due to its poor impedance matching.

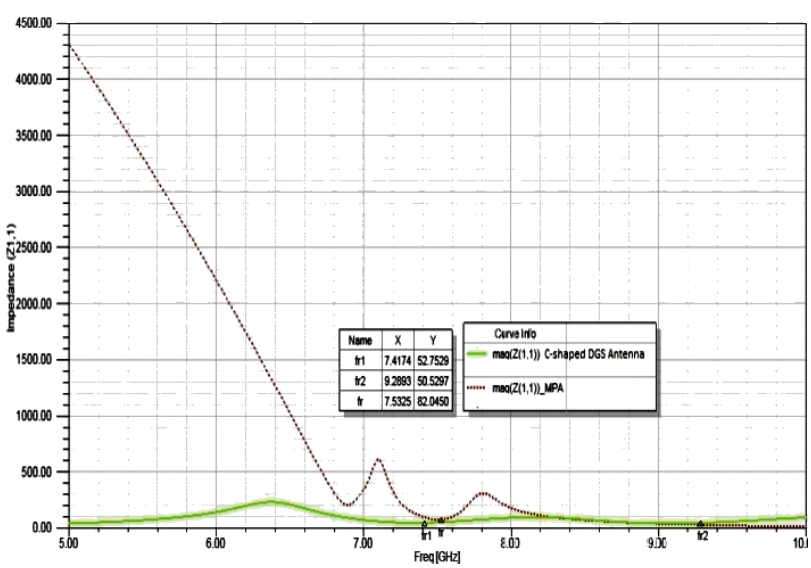

Fig 5: Simulated $Z_{11} v / s$ frequency plot for CRMPA and C-Shaped DGS antennas

\subsection{Peak Gain}

In Fig. 6, the continuous line shows the peak gain of the proposed C-shaped DGS antenna for dual operating bands. For proposed antenna, the simulated peak gains across dual operating bands are about $7.11 \mathrm{~dB}$ and $6.15 \mathrm{~dB}$ respectively. In case of CRMPA, the simulated peak gain of MPA is $8.2 \mathrm{~dB}$ as shown by dotted line in Fig. 6. Although the proposed antenna gives peak gain less than MPA but the achieved peak gains are more than $5 \mathrm{~dB}$ across dual bands which satisfy the condition of microstrip antenna.

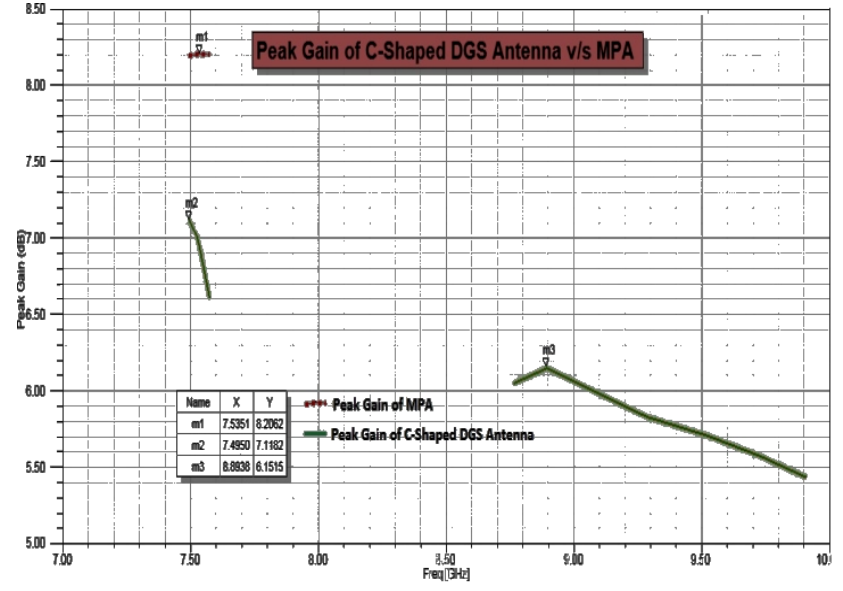

Fig 6: Simulated peak gain v/s frequency plot for CRMPA and C-shaped DGS antennas

\subsection{Radiation Pattern}

Fig. 7 present the simulated radiation patterns of CRMPA for $\mathrm{E}_{\theta}\left(\right.$ at $\left.\varphi=90^{\circ}\right)$ and $\mathrm{E} \varphi\left(\right.$ at $\left.\theta=90^{\circ}\right)$ when operating at 7.5331 GHz. In Fig.7, continuous trace shows the plot for $\mathrm{E} \varphi$ (at $\theta=$ $90^{\circ}$ ) whereas dotted trace shows the plot for $\mathrm{E}_{\theta}\left(\right.$ at $\varphi=90^{\circ}$ ). Fig. 8 and 9 show the simulated radiation patterns of proposed C-shape DGS antenna for $\mathrm{E}_{\theta}\left(\right.$ at $\left.\varphi=90^{\circ}\right)$ and $\mathrm{E} \varphi\left(\right.$ at $\theta=90^{\circ}$ ) when operating at 7.41 and $9.28 \mathrm{GHz}$ respectively for $\mathrm{C}$ and X-bands applications. In Fig. 8 and 9, continuous trace shows the plot for $\mathrm{E} \varphi\left(\right.$ at $\theta=90^{\circ}$ ) whereas dotted trace shows the plot for $\mathrm{E}_{\theta}\left(\right.$ at $\left.\varphi=90^{\circ}\right)$.

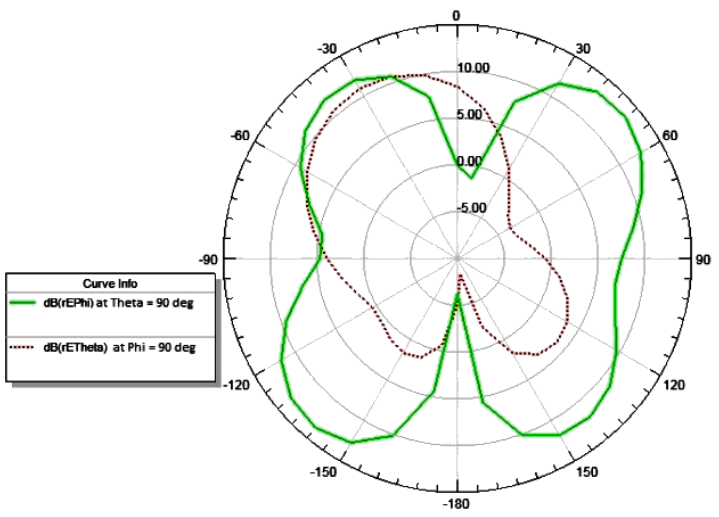

Fig 7: Simulated radiation pattern for CRMPA at 7.53 GHz for $E_{\theta}\left(\right.$ at $\left.\varphi=90^{\circ}\right)$ and $E \varphi\left(\right.$ at $\left.\theta=90^{\circ}\right)$

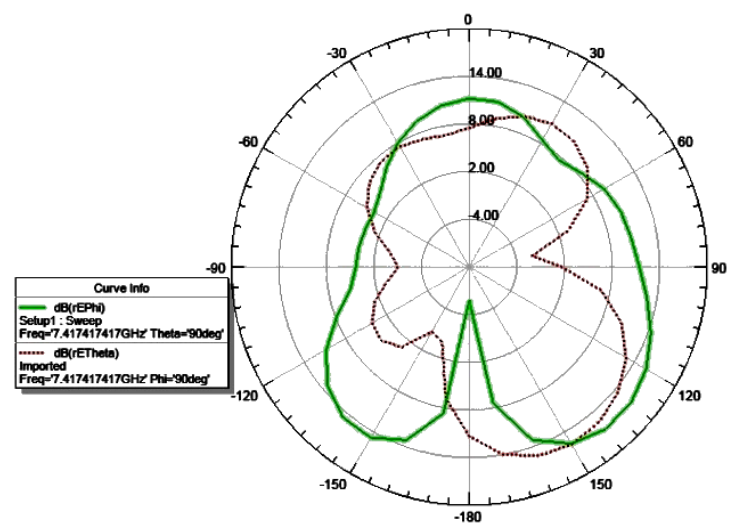

Fig 8: Simulated radiation pattern for C-shaped DGS antenna at 7.41 $\mathrm{GHz}$ for $\mathrm{E}_{\theta}\left(\right.$ at $\left.\varphi=90^{\circ}\right)$ and $\mathrm{E} \varphi\left(\right.$ at $\left.\theta=90^{\circ}\right)$ 


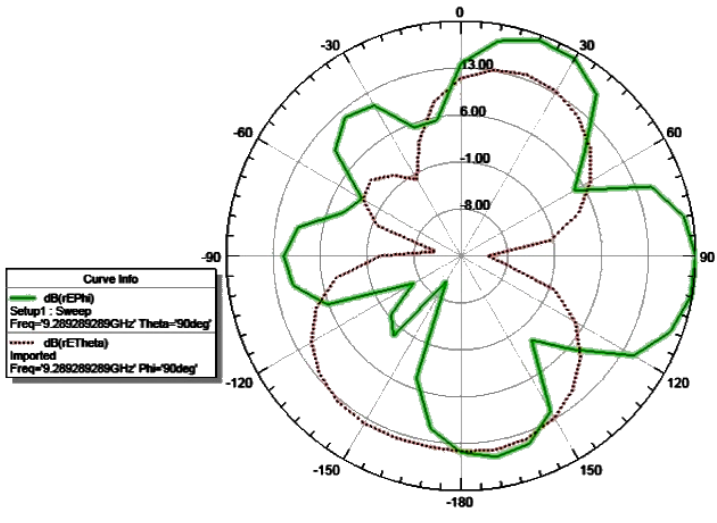

Fig 9: Simulated radiation pattern for C-shaped DGS antenna at 9.28 GHz for $\mathrm{E}_{\theta}\left(\right.$ at $\left.\varphi=90^{\circ}\right)$ and $\mathrm{E} \varphi\left(\right.$ at $\left.\theta=90^{\circ}\right)$

Table 2 summarizes the obtained simulation features of the designed antennas.

Table 2. Comparison of simulated results of both antennas

\begin{tabular}{|c|c|c|c|}
\hline $\begin{array}{l}\text { Sr. } \\
\text { No. }\end{array}$ & Parameters & CRMPA & $\begin{array}{l}\text { Dual Band } \\
\text { C-shaped } \\
\text { DGS } \\
\text { Antenna } \\
\end{array}$ \\
\hline 1. & $\begin{array}{ll}\begin{array}{l}\text { Resonating } \\
(\mathrm{GHz})\end{array} & \text { Frequency } \\
\end{array}$ & 7.53 & $\begin{array}{l}\mathrm{f}_{\mathrm{r} 1}=7.41 \\
\mathrm{f}_{\mathrm{r} 2}=9.28\end{array}$ \\
\hline 2. & Bandwidth (MHz) & 89 & $\begin{array}{c}914 \text { at } \mathrm{f}_{\mathrm{r} 1} \\
1182 \text { at } \mathrm{f}_{\mathrm{r} 2}\end{array}$ \\
\hline 3. & Return Loss (dB) & -11.78 & $\begin{array}{l}-30.79 \text { at } f_{\mathrm{r} 1} \\
-40.75 \text { at } \mathrm{f}_{\mathrm{r} 2}\end{array}$ \\
\hline 4. & VSWR & 1.69 & $\begin{array}{l}1.05 \text { at } \mathrm{f}_{\mathrm{r} 1} \\
1.01 \text { at } \mathrm{f}_{\mathrm{r} 2}\end{array}$ \\
\hline 5. & Impedance $(\Omega)$ & 82.04 & $\begin{array}{l}52.75 \text { at } \mathrm{f}_{\mathrm{r} 1} \\
50.52 \text { at } \mathrm{f}_{\mathrm{r} 2}\end{array}$ \\
\hline 6. & Peak Gain $(\mathrm{dB})$ & 8.2 & $\begin{array}{l}7.11 \text { at } f_{\mathrm{r} 1} \\
6.15 \text { at } \mathrm{f}_{\mathrm{r} 2}\end{array}$ \\
\hline 7. & Size Reduction of ground & - & $23 \%$ \\
\hline
\end{tabular}

\section{CONCLUSION}

A novel antenna design working in dual band i.e. C-band and $\mathrm{X}$-band has been successfully implemented in this Paper. The bandwidth of the CRMPA with same dimensions as mentioned in Table 1 at resonant frequency $\left(\mathrm{f}_{\mathrm{r}}\right)$ of $7.53 \mathrm{GHz}$ is $89 \mathrm{MHz}$ and also gives poor return losses $\left(\mathrm{S}_{11}\right)$ of $-11.78 \mathrm{~dB}$. While C-shaped DGS antenna gives bandwidth of $914 \mathrm{MHz}$ and $1.1828 \mathrm{GHz}$ at first and second band respectively with return losses of $-30.79 \mathrm{~dB}$ and $-40.75 \mathrm{~dB}$ respectively. Thus the bandwidth with $\mathrm{C}$-shaped DGS antenna is increased by $825 \mathrm{MHz}$ and $1.0938 \mathrm{GHz}$ for first and second band respectively than CRMPA. Also C-shaped DGS in the ground plane found to give a size reduction of about $23 \%$. The proposed antenna design is useful for satellite communications, RADAR and by some Wi-Fi devices.

\section{REFERENCES}

[1] Singh, Gurpreet, and Ranjit Singh Momi. "Micro strip Patch Antenna with Defected Ground Structure for
Bandwidth Enhancement." International Journal of Computer Applications 73 (2013).

[2] Singh, Gurpreet, and Anupma Marwaha. "Design of GShaped Defected Ground Structure for Bandwidth Enhancement." International Journal of Computer Applications 75 (2013).

[3] C. C. Lin, Y. C. Kan, L. C. Kuo, and H. R. Chuang, "A planar triangular monopole antenna for UWB communication," IEEE Microw. Wireless Compon. Lett., vol. 15, pp. 624-626, Oct. 2005.

[4] K. G. Thomas and N. Lenin, "Ultra wideband printed monopole antennas," Microw. Opt. Tech. Lett., vol. 49, pp. 1082-1085, May 2007.

[5] Viratelle, D. and R. J. Langley, "Dual-band printed antenna for mobile telephone applications," IEE Proc. Microwave Antennas Propagation, Vol. 147, No. 5, 381$382,2000$.

[6] Lelaratne, R. and R. J. Langley, "Dual band patch antenna for mobile satellite systems," IEE Proc. Microwave Antennas and Propagation, Vol. 147, No. 6, 427-428, 2000.

[7] Guo, Y. X., K. M. Luk, and K. F. Lee, "Dual-band slot loaded short circuited patch antenna," Electronics Letters, Vol. 36, No. 4, 289-290, 2002.

[8] Lu, J.-H., "Broadband dual-frequency operation of circular patch antennas and arrays with a pair of Lshaped slots," IEEE Transactions on Antennas and Propagation, Vol. 51, No. 5, 1018-1024, 2003.

[9] Liu, W. C. and W. R. Chen, "CPW-fed compact meandered patch antenna for dual-band operation," Electronics Letters, Vol. 40, No. 18, 1094-1095, 2004.

[10] Lau, K.-L., H. Wong, C.-L. Mak, K.-M. Luk, and K.-F. Lee, "A vertical patch antenna for dual-band operation," IEEE Antennas and Wireless Propagation Letters, Vol. 5, 95-98, 2006.

[11] Guterman, J., Y. Rahmat-Samii, A. A. Moreira, and C. Peixeiro, "Quasiomnidirectional dual-band back to-back E-shaped patch antenna for laptop applications," Electronics Letters, Vol. 42, No. 15, 367-370, 2006.

[12] Lau, K. L., K. C. Kong, and K. M. Luk, "Dual-band stacked folded shorted patch antenna," Electronics Letters, Vol. 43, No. 15, 789-790, 2007.

[13] Toh, W. K. and Z. N. Chen, "Tunable dual-band planar antenna," Electronics Letters, Vol. 44, No. 1, 108-110, 2008.

[14] Li, G. H., X. H. Jiang, and X. M. Zhong, "A novel defected ground structure and its application to a low pass filter," Microwave and Optical Technology Letters, Vol. 48, No. 9, 453-456, 2006.

[15] F. Y. Zulkifli, E. T. Rahardjo, and D. Hartanto, "Mutual Coupling Reduction using Dumbbell Defected Ground Structure for Multiband Microstrip antenna array" Progress In Electromagnetics Research Letters, Vol. 13, 29-40, 201. 